\title{
El discurs eclesiàstic davant el món visionari femení en els segles XVI i XVII
}

\section{The ecclesiastical discourse to the female visionary world in the XVI and XVII centuries}

Rosa Ma Alabrús

ralabrusi@uao.es

Universitat Abat Oliba CEU (Barcelona)

Resum: A l'article es descriu l'evolució del discurs eclesiàstic davant la religiositat femenina des de les primeres manifestacions d'il luminisme. S'incideix en la significació de l'obra de Teresa de Jesús a la construcció del món visionari femení i s'analitzen especialment les actituds sobre el mateix de l'arxidiaca Juan de Horozco, del franciscà Gerónimo Planes i el carmelita descalç Antoni de Sant Maties Carbó. Es demostra l'esforç per conjugar la legitimitat de les visions de Teresa de Jesús amb els progressius recels eclesiàstics sobre l’imaginari femení.

Paraules clau: visions, mortificacions, oració mental, oració vocal, espiritualitat, església, dones

\begin{abstract}
The article describes the evolution of ecclesiastical discourse about female religiosity from the first manifestations of Illuminism. It stands the significance of the work of Teresa of Jesus in the construction of the female visionary world. Attitudes on the question of Archdeacon Juan de Horozco, the Franciscan Gerónimo Planes and the Discalced Carmelite Maties de Sant Antoni Carbó are exposed. It demonstrated the effort by combining the legitimacy of the visions of Teresa with progressive ecclesiastical misgivings about the female imagination.
\end{abstract}

Keywords: Visions, Mortifications, Mental Prayer, Oral Prayer, Spirituality, Church, Women

\footnotetext{
* Aquest article s’insereix al projecte I+D+I: "La religiosidad femenina en la Cataluña de la época moderna" (MINECO, con referencia HAR 2014-52434-C5-4-P)
}

DATA PRESENTACIÓ: 01/07/2016 ACCEPTACIÓ: 20/09/2016 •PUBLICACIÓ: 14/12/2016 
El fenomen profètico-visionari va tenir múltiples expressions a l'època medieval. Des del segle XIV no van faltar esforços de disciplinament, en especial, adreçats a les manifestacions femenines. En aquest sentit, és rellevant la trilogia de Jean Gerson (1401-1423), que concedeix transcendental importància a la Discretio Spirituum i la seva missió de delimitar el que és el presumpte carisma individual respecte a la valoració eclesiàstica de la problemàtica de les visions. Pel que fa a la credibilitat de les mateixes llur actitud és optimista. A la monarquia hispànica, el cardenal Juan de Torquemada, en els seus comentaris a les revelacions de Santa Brígida de Suècia, va defensar així mateix la legitimitat de les visions femenines.

L'Església passaria per diverses fluctuacions al llarg de la reforma catòlica. El meu objectiu en aquest article és recórrer l'evolució del discurs postridentí davant del món visionari de les monges del Barroc, arribant el meu recorregut fins a l'anàlisi de les obres del franciscà Gerónimo Planes i del carmelita Antoni de Sant Maties, les quals, al meu parer, marquen una fita fonamental en la fixació del cànon eclesiàstic respecte a les visions femenines.

Si a començaments del segle XVI el cardenal Cisneros, en el seu anhel reformista, va donar suport a la religiositat femenina i a la tasca de beates com María de Santo Domingo (beata Piedrahita), el cert és que aquesta va acabar essent processada, entre 1508 i 1510, pels arravataments i revelacions amb components eròtics que semblava tenir, considerats com a inquietants per la Inquisició (García Hernán 2013; Pérez 2014). La prevenció davant del món dels il luminats va obligar a actuar el Sant Ofici de Toledo, el qual, a l'edicte de fe de 1525, va plantejar quaranta-vuit proposicions que es consideraven herètiques i que van atribuir-se als qui s'anomenaven a ells mateixos «il luminats, enllumenats, abandonats i perfectes». Entre ells, hi hagué beates com Isabel de la Cruz, Francisca Hernández o María de Cazalla, al costat d’homes com Pedro Ruíz de Alcaraz, Francisco Ortíz o Bernardino de Tovar. El que més preocupà a l'Església i pel que va actuar la Inquisició, fou pel pregonament, per part dels il luminats, de l'abandó sense límits, el lliurament absolut a Déu, el deixament, sovint acompanyat d'una forta càrrega emocional i, alhora, barrejat amb manifestacions de vida irregular (Caro Baroja 1978: 468-470; Márquez 1980). Aquest espiritualisme il luminat acompanyaria els primers jesuites, la qual cosa va motivar el ferotge refús del dominic Melchor Cano, amb les seves conegudes crítiques a Ignacio de Loyola, el 1556. ${ }^{1}$

L’imaginari fóra reprès per Teresa de Ávila al seu Libro de la Vida. El va escriure entorn de 1565, per manament del seu confessor, el dominic García de Toledo. En aquesta obra narrava la seva experiència visionària i definia els seus arrauixaments, elevacions o vols de l'esperit (Jesús, T. de 2012: 108-109). El llibre, a la seva època, va circular manuscrit amb opinions favorables, però carregades de matisos. El dominic Báñez i Juan de Ávila resolgueren que «aquest llibre no està per a que es comuniqui a qualsevol, sinó als homes doctes i d'experiència i discreció cristiana». En canvi, per a l'inquisidor general Gaspar de Quiroga el llibre era de «lectura molt segura, vertadera i profitosa» (Alabrús i García Cárcel 2015: 19-27 i 205-220). ${ }^{2}$

1 Biblioteca Universitaria de Barcelona (BUB). Ms. 1010, pp. 7-9. El dominic Gaspar Vicens reflecteix les crítiques de Cano contra Ignasi de Loyola i la Companyia de Jesús a la Miscelánea político-eclesiástica.

2 A l'obra, els autors palesen com l'inquisidor Gaspar de Quiroga va intentar racionalitzar els recels que suscità l'espiritualitat i la difusió de la mateixa a través de l'escriptura de la mare Teresa d'Avila en vida. 
L'obra de Teresa va suposar la voluntat de compaginar bé la realitat i l'imaginari, el món contemplatiu i visionari i la vida activa. La monja abulenca va saber palesar una extraordinària capacitat d'equilibri que la va portar a no posicionar-se en les batalles teològiques i jurídiques que es desenvoluparen a la cojuntura històrica que va viure. En aquest sentit, és especialment significatiu el seu eclecticisme a l'enfrontament entre dominics i jesuïtes. Es pot dir que inicialment va preferir els jesuïtes, però buscant sempre suport i legitimació a l'orde dels Predicadors.

Si la primera Teresa fou una visionària, amb forts deliris místics, tal i com es reflecteix a la seva pròpia autobiografia, rere els actes de fe de Sevilla (1557) i Valladolid (1558-1559), arran de la psicosi antiprotestant difosa per l'inquisidor Fernando de Valdés, començaria la seva etapa fundacional (Carmel de Sant Josep, 1562), en la qual les seves revelacions minvarien i es dedicaria més a resoldre la inmensa problemàtica suscitada per les fundacions. La Teresa fundadora no és la Teresa dels èxtasis i la transverberació. En els seus escrits intentà rebaixar la rellevància de les seves pròpies vivències, tal i com li va recomanar el jesuïta Francesc de Borja, el qual havia conegut mitjançant el seu altre confessor, el també jesuïta Juan de Prádanos. Frases i expressions de Teresa en el Libro de la Vida -«durava tan poc això de la unió amb Deu que no sé si era Ave Maria» o «encara que poques vegades es perd el sentit, alguna volta m'ha esdevingut a mi perdre'l del tot, poques i per poca estona»- així ho posen de manifest (Jesús 2012: 43 i 113).

La monja d’Àvila, davant els actes de fe de Valladolid i la proclamació de l'Índex de Valdés, el 1559, respongué amb un extraordinari silenci. Encara que fou una dona llegida, acabà per assumir les seves conseqüències:

\begin{abstract}
Cuando se quitaron muchos libros de romance, que no se leyesen, yo sentí mucho, porque algunos me daba recreación leerlos y yo no podía ya, por dejarlos en latín. Me dijo el Señor no tengas pena, que yo te daré libro vivo. Yo no podía entender por qué se me había dicho esto; después, desde a bien pocos días, lo entendí muy bien, porque he tenido tanto en qué pensar y recogerme en lo que veía presente, y ha tenido tanto amor el señor conmigo para enseñarme de muchas maneras, que muy poca o casi ninguna necesidad he tenido de libros. Su Majestad ha sido el libro verdadero a donde he visto las verdades. ¡Bendito sea tal libro, que deja imprimido lo que se ha de leer y hacer de manera que no se puede olvidar! (Jesús 2012: 142).
\end{abstract}

Rere la prohibició de les obres de Francisco de Osuna, Bernardino de Laredo, Bernabé de Palma, Alonso de Madrid, Alonso de Guevara, Pedro de Alcántara, Vicent Ferrer, Luis de Granada i de tants d'altres, Teresa va canviar: llegí menys i visqué més. Respecte a la misogínia creixent, tal i com ha assenyalat A. Weber (1996 i 2003) o Ma José de la Pascua (2014), va recórrer a la retòrica de la feminitat. ${ }^{3}$ Sens dubte, s'esforçà, davant les monges, a delimitar el que és arravatament i

3 A. Weber (1996 i 2003: 107-125) i M. J. Pascua (2014: 23-51) sostenen que Teresa de Jesús es recolzà en el recurs estratègic a la inferioritat femenina com a «captatio benevolentiae», que parteix d'un noquejament aparent del gènere femení, encara que fos perfectament conscient de les coaccions i absències de llibertat que les dones patien. Així ho blasmà Teresa de Jesús a «Las Moradas» (Jesús 2012: 544). També ho palesen T. Álvarez (1965), J. A. Marcos (2001) i S. 
embadocament: «I deixen -se embeure, i mentre més es deixen, s'embeuen més perquè s'aprimen més el natural, i en el seu senderi els sembla arravatament, i li dic jo embadocament, que no és altra cosa més que estan perdent el temps i la salut» (Jesús 2012: 506).

A la fi de la seva vida va despuntar un nou corrent d'il luminats, el de Llerena, denunciat pel dominic Alonso de la Fuente el 1575, el qual va subratllar la fragilitat femenina, davant el mateix, i feia les dones «fàcil presa, per llur ignorància, de les presents revelacions divines» (Huerga 1978; García Cárcel i Moreno 2000: 277-278). ${ }^{4}$ La misogínia es disparà i el debat sobre la il lusió i el discerniment, entre la veritat o la falsedat del món visionari, restà obert.

La polèmica sobre les visions va motivar àdhuc que, amics de Teresa com Fra Luis de Granada, Juan de Ribera o Juan de Àvila, fossin acusats d’il luminisme (Callado 2016), i companys seus, com Juan de la Cruz (Subida al Monte Carmelo, 1578), recomanessin fugir d'aquestes experiències, negant-se a «examinar si són bones o dolentes». L’autobiografia de Teresa havia ja suscitat sospites, però acabà essent acceptada perquè va saber, en tot moment, unir la religiositat institucional i el seu carisma personal. El text de la Censura del dominic Báñez, que s’inclou en la propia Vida de Teresa, és tot un exponent dels problemes de discerniment que l'obra de la religiosa havia ja generat (Jesús 2012: 230-231). No obstant, seria després de la mort de la monja abulenca (1582) quan es desencadenaria un discurs doctrinari de l'Església, amb majors recels davant la religiositat femenina. Des del 1589, Alonso de la Fuente deixà clares les seves crítiques antiteresianes, convençut que l'acció d'escriure, per part d'ella, era fruit de la intervenció diabòlica. Tampoc acceptava que una dona es mostrés com a mestra d'oració i volgués ensenyar a homes doctes i lletrats. El dominic condemnava la doctrina de l'oració amb silenci, mental en definitiva, com a suficient per a comunicar-se amb Déu. La considerava influenciada pels espirituals alemanys (Tauler, Herph o Blosio) i apostava per l'oració vocal (E. Llamas 1972). Amb tot, De la Fuente no arribava a considerar-la una enganyadora, ja que «parla tan planerament, bo i dolent, i amb tanta gana d'encertar, que no deixa dubtar de la seva bona intenció» encara que sí considerava pertinent que semblants esperits com el de la mare Teresa «fossin examinats, per haver vist en el nostre temps gent burladora sota color de virtut, que tant més, convé emparar els que amb el color sembla que tenen la veritat de la virtubs (Llamas 1972: 312-316). ${ }^{5}$

Poc després, el 1591, el també dominic Juan de Orellana palesà la seva disconformitat amb els tres llibres de Teresa de Jesús (Libro de la Vida, Camino de Perfección i Las Moradas), ja que:

Ros (1997: 62-80).

4 Els autors dediquen un capítol al món de la il lusió femenina.

5 E. Llamas (1972: 312-316), en el seu llibre sobre Santa Teresa de Jesús y la Inquisición española, aporta la Carta al Consejo que escriví el dominic Alonso de la Fuente, el 26 de agosto de 1589, contra Teresa de Jesús; Archivo Histórico Nacional. AHN. Inquisición, Legajo 2072, no 43. 


\begin{abstract}
Señalan varios grados de oración, hasta llegar a uno que la madre Teresa llama de total unión y perfecta contemplación, en que el alma està toda unida con Dios y los sentidos y potencias del alma todas: entendimiento, memòria, voluntat sin ninguna operación y Dios, por acción suya se junta con el alma en el centro de ella, absortes y perdidas a las potencias (...). En esta unión dice que no queda libertad al alma y que Dios la enseña por sí mismo y es su maestro, y vee el alma grandes visiones y revelacions, que no se pueden decir, hasta ver con visión intel lectual, aunque no con los ojos del alma, la Santísima Trinidad y las tres Personas distintes. Esta doctrina es errònia y, a mi juicio, herètica de los Entusiastas (...) es decir que a muchas mujeres engaña esta doctrina, con el diabló transfigurado en ángel de luz (...) Agravese esta mala doctrina con que la autora della dice que Dios se la ha enseñado y dicho que la escribiera (Llamas 1972: 434-435). ${ }^{6}$
\end{abstract}

A la conjuntura d'increment dels filtres a l'espiritualitat femenina hi van contribuir diversos elements. Un primer factor a tenir en compte és la imbricació de les visionàries a l'àmbit de la política. El primer exemple, el més conegut, atès que va tenir un enorme impacte, fou el de la religiosa dominica de Lisboa, María de Meneses o María de la Visitació. Aquesta monja, nascuda el 1551, va tenir infinitat de visions. El seu moment àlgid fou el 1575, quan el seu món visionari, davant les primeres denúncies, fou recolzat i legitimat per fra Luis de Granada. Després que el 1588 es posicionés contra els drets de Felip II al tron de Portugal, va caure en desgràcia política (Imirizaldu 1977; Kagan 1992 i Martínez-Burgos García 1997: 464-475).

Quantes beates o monges que gaudiren d'extraordinari prestigi, tant a la cort com a la pròpia Església, foren després estigmatitzades com a heterodoxes per desavinences conjunturals amb el poder polític? A part de la ja esmentada María de la Visitación, caldria situar aquí personatges com Catalina de Cardona, Lucrecia de León o, més tard, María de Ágreda. La desconfiança cap a les visions va venir, doncs, per la por a les embaucadores, amb les implicacions polítiques fluctuants de les visionàries.

D’altra part, no només es qüestionarà l'espiritualitat teresiana, sinó també la seva tasca fundacional. El mateix va ocórrer o fins i tot es va agreujar quan les seves companyes intentaren de prosseguirles. Maria de San José, prelada a la fundació de Sevilla, assegura, a la seva autobiografia, com els carmelites calçats la difamaren, al legant que era una «relaxada» o «deixada», i per tenir massa «afició» al pare Gerónimo Gracián. Amargament, es queixà com el recurs de la humilitat i l'autonegació li serviren de poc davant del propi provincial de l'orde del Carmel. Afegeix que els seus detractors únicament tenien contra ella «haver fundat, per igual, que la seva predecessora Teresa de Jesús». Lamenta com aquells que havien recolzat abans els procés fundacional, ara «per por o per pretensions» negaven la veritat i queien «a l'abisme de la mentida». ${ }^{7}$

6 Llamas aporta l'Informe o Calificación condenatoria que va escriure el també dominic Juan de Orellana, el 22 de abril de 1591, en detriment de l'espiritualitat teresiana.

7 BNM. Ms 2176. San José, María (s/d.: 98-111 i 134-144) Papeles recogidos por Fray Lorenzo de la Madre de Dios, carmelita descalzo.

SCRIPTA, Revista internacional de literatura i cultura medieval i moderna, núm. 8 / desembre 2016 / pp. 287-300 ISSN: 2340-4841 · doi:10.7203/SCRIPTA.8.9300 
El segon factor a tenir en compte fou la demonomania estesa per Europa a partir de l'obra clàssica de Juan Bodino (1580). L'obsessió pel dimoni, en relació amb la màgia i les visions, ja es venia plantejant amb anterioritat. D’aquesta manera destaquen les obres de Martín de Castañega (Tratado de las supersticiones, hechicerías y varios conjuros y abusiones y de la posibilidad y remedio dellas, 1529) i Pedro Sánchez Ciruelo (Reprobación de supersticiones y hechicerías, 1538), però no seria fins a finals del segle XVI i principis del segle XVII que el discurs sobre el dimoni s'intel lectualitzaria encara més. Gairebé al mateix temps que l'interès pel diable es va estendre la fixació per les bruixes. Només la conjuntura dramàtica dels processos de Zugarramurdi, amb els coneguts actes de fe del 7 i 8 de novembre de 1610, on diverses persones que es resistiren a acceptar les acusacions inquisitorials de Logroño, foren cremades vives, semblà imposar un cert racionalisme (a partir dels Memoriales e Instrucciones d'Alonso Salazar y Frías enviats al Consell de la Suprema, on posava en evidència la manca de proves de les condemnades) malgrat que la discussió, sobre si eren creỉbles o no, els presumptes contactes de les bruixes amb els dimonis i la credibilitat de les visions de les dones religioses, continuà (Morgado 1999; Tausiet i Amelang 2004). ${ }^{8}$

Proliferaren diversos tractats eclesiàstics sobre la qüestió, com els dels jesuïtes Benito Pereira (Addversus fallaces et superstitiosas artes, id est, de magia, de observatione somniorum, et de divinatione astrológica, 1591); Luis de la Puente, que va advocar a les seves Meditaciones (1605) i a la seva Guía Espiritual (1609) per una visió fonamentada en la contemplació intel lectual, per evitar la influència del dimoni, o Martín del Río (Disquisitionimum magicarum libri sex: quibus continetur accurata curiosarum artium vanarum superstitionum confutatio, utilis theologis, jurisconsultis, medicis, philologis, 1612). Jesuïtes i dominics pretenien una major racionalització de la via sensitiva defensada per la mare Teresa.

Igualment, Juan de Horozco es va significar entorn al món visionari. El 1588, publicà un Tratado de la verdadera y falsa profecía en el qual va intentar fixar les fronteres entre la realitat i l'imaginari. En la línia de Teresa de Jesús, que establia, en El libro de la vida dos tipus de visions: les imaginàries i les intel lectuals, l'ardiaca de Cuéllar no condemnà la capacitat de profecia de la dona religiosa, però si que atorgà major protagonisme a la visió intel lectual, per sobre de la imaginària. Horozco fixava diverses regles contra els falsos profetes i visionaris, sense distinció entre dona i home. Encara sembla participar de l'antic optimisme gersonià cap a les visions, malgrat que siguin visibles les mostres de vacil lació (Horozco 1588). ${ }^{9}$

Els franciscans no tardaren a tractar el tema. Fra Juan de los Ángeles, al seu Diálogo de la conquista del reino de Dios (1595), va escometre contra les monges visionàries, a les que acusà de que «a costa de la virtut, que no tenien, es feien riques». No gaire més tard, el també franciscà Francisco Daza, el 1610, matisà a Teresa de Jesús, assenyalant tres tipus de visions: la sensitiva, la imaginària i la intel lectual. Daza repudiava el món purament sensitiu i realçava la visió intel lectual (Ángeles 1595

8 A partir de les obres d'Arturo Morgado (1999) i d'Amelang (2004) es pot constatar la progressiva intel lectualització del dimoni a finals del segle XVI.

9 Horozco (1588) ho blasma en els capítols XV, XVI, XVII y XVIII del Tratado de la verdadera y falsa profecía. 
i Daza 1610). De forma semblant als tractadistes anteriors, el carmelita descalç Tomàs de Jesús, a la seva obra De contemplatione divina, libri sex (1620), afirmà que el misticisme no és una qüestió de visions extraordinàries i establí la jerarquia entre la visió adquirida i la infosa. L'una, obra de l'enteniment i la voluntat; l'altra, de la gràcia divina.

Els examinadors posteriors de les visions femenines reconeixeran els mèrits de Teresa, però s'esforçaran a penalitzar els egos excessius de les monges barroques. El propi procés de beatificació i canonització de Teresa fins a la seva feliç culminació (1622), obligà la institució eclesiàstica a reavivar el vell problema de la gràcia, confrontant la providència divina amb els mèrits de la persona agraciada.

Obertament reaci a les revelacions femenines es manifestà el franciscà Gerónimo Planas, dotze anys després de la canonització de Teresa. En el seu Tratado del examen de las revelaciones verdaderas y falsas y de los raptos (1634) ressaltà el paper de la jerarquia eclesiàstica, a l'hora de determinar la genuïna santedat femenina. En matèria de Discretio Spirituum va reflectir que l'era dels miracles no havia conclòs, i que des de l'origen de l'espècie, la divinitat havia tramès missatges als homes a partir de visions, somnis i profecies, i continuaria fent-ho fins al final dels temps. No mostrà cap objecció als exercicis d'autodiscerniment d'antuvi practicats pels grans sants cristians, però, nogensmenys, va voler deixar clar el protagonisme de l'Església en detriment de la religiositat femenina.

Planas era mallorquí, nascut el 1564. De jove es traslladà a València, per continuar els seus estudis, i allí ingressà a l'orde dels franciscans. Morí el 1635 a la cartoixa mallorquina de Valldemosa. Es centrà a subratllar la propensió de les dones a caure en les ficcions de l’imaginari sensitiu, car són de «naturalesa feble i fràgil», i això, afirma, les fa caure més fàcilment en les revelacions i suggestions diabòliques. Quant a les condicions morals, la seva tesi és que la dona és un arma en mans de Lucifer, contra l'home. La seva crítica incideix en la dona-temptació, enganyadora: «Són talment les dones l'instrument més eficaç que el dimoni hagi tingut i tingui per enganyar els homes, i per això Satanàs les empra més ordinàriament, entre els gentils, per enganyar-los». A més va adjudicar a la dona un reguitzell de vicis i de posseïr «vanitat, hipocresia, enveja, ambició, cobdícia, luxúria...» (Planas 1634: 267-268 i Poutrin 1995: 62-65). La conclusió de Planas és rotunda: «Han de ser les autoritats eclesiàstiques les que estableixin les fronteres entre la veritat i la falsedat, els criteris objectius, en definitiva, el discerniment».

L'esforç de Planas és extraordinari en emfatisar la gràcia divina per damunt les pròpies qualitats carismàtiques de l'individu. La via purgativa no condueix, per a ell, a la via mística. Les revelacions no s'aconsegueixen pas per la pròpia voluntat ni per l'estudi o l'exercici, sinó per la bondat divina. L’enteniment és il luminat i elevat per conèixer les coses que li són proposades i representades. Utilitzà l'exemple de Teresa per a posar de relleu que no n'hi ha prou de la voluntat per tenir revelacions, tot qüestionant la via purament sensitiva. 
Un altre tractadista català, més jove que Planas, el carmelita Antoni de Sant Maties Carbó, nascut a Figueres (1595), subprior del convent de Sant Josep de Barcelona, intentà igualment fixar el cànon de la religiositat femenina a la primera meitat del segles XVII. Fou mestre i guia espiritual de no poques monges en diversos monestirs barcelonins (Immaculada Concepció, Sant Jeroni, Valldonzella, Santa Clara, Santa Isabel o Elisabets, Les Magdalenes, Els Àngels i Jonqueres). Sens dubte, li preocupava la qüestió de les revelacions $i$ la capacitat visionària de les seves monges, a les que confessava amb freqüència. Per això va decidir escriure diverses obres d'espiritualitat adreçades a «les seves filles», en català. ${ }^{10}$

Escriví, a més, cartes pedagògiques, a les seves deixebles, recomanant-los evitar l'excés de meditació i contemplació. A la carta que escriu a la germana Maria, li recorda, en aquest sentit, l'exemple de Teresa de Jesús: «Sien sempre en l’ànima de vosa caritat Hermana María, nostra Santa Mare Theresa, en lo capítol dotse de sa Vida, tractant del gran bé que es portar a Cristo present en algún pas y misteri de sa Vida o Passió Santíssima». ${ }^{11}$

En lloc d'exercir una vida espiritual contemplativa, Sant Maties orientà la religiosa, en diverses frases, a seguir amb el seu progrés espiritual: a una etapa inicial, com a principiant, li seguiria una segona, posterior, més complexa, d'assimilar les passes de la Passió de Crist. Li recomanava, per això, tenir en compte sis filtres:

1. $\quad$ El primer, el de seguir les penes i penitències a cada passa.

2. El segon, el de plantejar-se qui patiria aquestes penes.

3. El tercer, per a qui o per qui patiria aquestes penes.

4. $\quad$ El quart, la causa per la que pateix o patirà les penes.

5. El cinquè, l'amor gran amb el qual patirà les penes.

6. El sisè, el gran exemple de virtut que deixaria a la mesura o manera que es pateixi.

En el patiment, la religiosa havia d'evitar fingir i enganyar: «La Rao de açò es perquè de la Meditació sols se à de usar, lo que es menester per a mourer e inclinar la voluntat (...). Molt se à de meditar; però ai al revés, prest està moguda, prest se à de dexar la meditació». Igualment, havia de mostrar resignació, silenci i control de les emocions, car Jesucrist, malgrat el que va patir, mai s'havia queixat «en lo fort de La Passió; aquella Humilitat, Paciencia, Fortalesa y Magnanimitat ab que mostrà juntament ab moltes altres virtuts. Pus en los majors turments oprobis y menyspreus que mai se son vistos, nis veuran, mai se quexà, ni tornà per si. Com un manso Anyell» (Sant Maties Carbó 1650: 2).

Pel carmelita figuerenc, manifestar les passions podia ésser obra del dimoni, per la qual cosa aconsellà, a la germana Maria, llegir el capítol vint-i-dos de La Vida de Santa Teresa i el setè de Las Moradas:

10 Vegeu a Gras (2013) les dades aportades sobre Antoni de Sant Maties Carbó (1595-1668).

11 Biblioteca de Catalunya (BC). Ms. 4164. Sant Maties Carbó, A. de. (1650 : 1) Cartes i epistolaris.

SCRIPTA, Revista internacional de literatura i cultura medieval i moderna, núm. 8 / desembre 2016 / pp. 287-300 ISSN: 2340-4841 · doi:10.7203/SCRIPTA.8.9300 
És excel.lent manera de aprofitar y molt en breu; y aquí posava cuidado en portar ab si esta preciosa companyia y en aprofitarse della y en obrar de veras amor a est Senyor, a qui tant deu (...) Est modo de aportar a Christo ab nosaltres aprofita en tots estats y es un medi seguríssim per anar aprofitant en lo primer de principiants; y per arribar en breu, al segon grau de oració y per que los postrers y últims sien segurs del perill del dimoni y après el capítol vint y dos de La Vida y en los capítols setè de las Sextas Moradas diu moltes y molt extremades coses per aquest mateix propòsit, lo qual me à mogut à escriurer à vosa Caritat en esta Carta, un modo per a saber portar presents los dits passos y misteris y per a saber meditar y considerar lo que en dits passos per nostre Amor feu y obra (Sant Maties Carbó 1650: 1).

Rebutjà el goig, el plaer i l'emoció durant les revelacions divines:

\begin{abstract}
Si troba que estava molt alegre, done gracias al Tresor per aquella mercè, demanantli gràcia perquè de allí avant o pugue continuar (...) Si se troba Divertida o Molt Trista; face actes de pensar y de dolor de aquell divertiment y descuyt, demanant a Nostre Senyor gràcia per a de veras esmanarse y fent propòsits de nou més ferms de fero y axi de fet, aquí mateix des de aquell punt, fero, cocs posarse en la Presencia, que antes havia perduda y anant de allí en avant en mes cuidado (Sant Maties Carbó 1650: 4).
\end{abstract}

Finalment, per a tots aquells que percebessin la inclinació cap a la unió amb Déu, Sant Maties propugnà, com la mare Teresa, només estar-hi «una estona» i «poques vegades» seguint el capítol tretzè de La Vida reforçant l'argumentació de que la unió és tan efímera que no pot dur a la pèrdua del control de les emocions:

\begin{abstract}
Mirem los que discurren molt ab lo enteniment, traent moltas coses, de una cosa y molts conceptes ò consideracions della; estos puc dir que miren que no els vaja tot lo temps en açò, per que enquara que es molt meritori, no ocupen tot lo temps en açò; sinó que representen davant de Christo y sens cansanci del enteniment, se estiguin parlant y regalant ab sa Divina Magestat, sens cansarse en com pondre raons, sinó presentantli necessitats, ò suas, ò agenas, per que las remedie y la Rao que te per a suffrirnos allí y apres més ayant en lo mateix capítol diu axi: Bo es quo qui te oració sobre lo Pas de las Columnas, Discurre un rato, pensant las penes que Christo en ella pati y perquè las pati y qui es qui las pati, y lo Amor al que las pati. Pero que nos canseen anar sempre cercant aço, sinó que apres de fer aço un rato, se estigue allí ab los Senyor, ab lo enteniment callat y quedo (...) sens discurrir. A las hores estant així, si pot ocupe lo enteniment en mirar y avivar la fe, que Aquell Soberano Tresor lo mira y penetra tot; y estant axi façeli companyia, parleli, demaneli, humilles devant dell, regales ab ell, recordantse que no mereix estar allí. Quant pugue fer aço, enquara que sie al principi de començar la oració, trobara grans profits (...). A de passar tota la oració en discurrer y meditar; sinó apres de haver fet aço, un rato, à de passar lo que pugue del demes temps, com Teresa Santa Mare à dit. Après de lo qual podrà tornar altre vegade à la meditació y discurs (Sant Maties Carbó 1650: 3).
\end{abstract}

En el cas que la passió, davant la unió amb Déu, es donés en excés, el que, segons sembla, li esdevenia a ell mateix, segons el testimoni de sor Mariàngela Berart (agustina de les Magdalenes): «Patia freqüentment arravataments i li fou forçós portar oberta la roba que li queia sobre el cor, perquè no podia sofrir la 
cremor; per la mateixa raó, no podia tenir oració entre parets, sinó en llocs espaïosos, passejant-se, o sortint a l'horts ${ }^{12}$ el pare Sant Maties suggeria el sacrifici i la mortificació per a neutralitzar els sentits en general.

La mortificació corporal és tractada pel propi frare carmelita en el seu Tractat de la perpetua mortificació exterior i interior i la justifica de la manera següent: «Responc que mortificació no és altre cosa que negació de lloc, ocasió y facultat per a ferse lo que naturalment se desitja y apeteix fer. No donant, ni concedent lloc, ni ocasió, ni facultat per a fer-ho».13

Per últim, Antoni de Sant Maties alliçona epistolarment a Maria, no oposant-se a l'oració mental, però advertint-la que hi ha dues formes d'exercitar aquesta oració: la infusa o sobrenatural, la primera, en què l'ànima, mitjançant els actes dels dons de l'Esperit Sant, és elevada de forma sobrenatural, amb intervenció divina i enteniment i voluntat elevats. L'altra és l'oració adquirida o natural, en la qual l'home, cridat per la gràcia i l'auxili diví, aprenent pel seu propi treball o esforç, procura alçar el seu esperit, sense oblidar la meditació i discurs de l'enteniment (Sant Maties Carbó 1650: 1). Emet un discurs que pretén recuperar la mística teresiana conduint les emocions, sense desconfiar de les religioses.

El místic català, a la fi del tom primer del seu Tratado sobre la mortificación, accepta la visió i la unió amb Déu en homes i en dones, però no només mitjançant l'Esperit Sant (més propi dels primers «deixats» del segle XVI); i matisa les preferències exclusives per l'oració vocal, a partir de l'exemple de la pròpia Teresa de Jesús, a la qui va tenir present tothora:

\begin{abstract}
Oración mental, com diua la Santa mare (Teresa) no es altra cosa sino una consideració ab la qual lanima posada a devant de Deu adverteix ab qui parla, lo que demana y qui demana y a qui. La vocal segons la mateixa Santa es la que es fa ab la boca. Qualsevol destas dos fetas y tingudes ab la deguda y iusta atencio, atendencia y advertencia de Deu y a lo demes, es tan aceptada y agradable com Diu Sant Agustí: alcansa de sa Divina Majestad lo que en ella se li demana. D'acò com dic qualsevol oració fins la vocal, perque esta tinguda com he dit. Com diu Nostra Santa Mare: es vocal y iuntament mental. Pero al revés. Qualsevol destas dos feta y tinguda ab actual distracció y divertiment. Com diu Sant Gregori, no es oyda del Señor y aixi no alcansa lo que en ella se demana. De lo qual no hi ha que maravellar pus est modo de orar. Es tal que del Diu Nostra Santa Mare, estas palabras. Qui tingues costum de parlar en la oració; ab lo Señor: com qui parla ab un esclau que no adverteix si diu mal o be, sino lo que li ve a la boca y ho té ia de costum per ferho aixi altres vegades. Diu la Santa: est modo de oració, nol tinc per oració. Ni plegue a Deu la tinga ningún cristia desta manera. Esta es la primera divisio de la oracio. ${ }^{14}$
\end{abstract}

12 BUB. Ms. 991. Sant Josep, J. de. Anales de los carmelitas descalzos de la provincia de San Josef, p. 527

13 BUB. Ms. 31. Sant Maties Carbó, A. de. Tractat de la perpetua mortificació exterior i interior, p. 251

14 BUB. Ms. 31. Sant Maties Carbó, A. de. op. cit., p. 320 
El subprior del convent de Sant Josep de Barcelona fa unes finals Advertencias sobre quatre graus de oracio que posa Nostra Santa Mare Theresa de Jesus que son de Reculliment Natural, Sobrenatural, Quietuty Unió:

Lo primer grau com diu N. Santa Mare T. es un Reculliment y Retiro interior que se sent en l'anima, sentist ses Potencies, retirades, recullidas y ocupadas, allí dintre de la mateixa anima, de modo que la mateixa anima ve a alcançar dit Reculliment, Suposada y mediant la gracia Divina (sens la qual nos pot ningún be) après, mediant ses propias forças y diligencias. Per lo qual, dit Reculliment se diu també Acquirit i Alcançat.

Lo segon grau, ço es de Reculliment Sobrenatural com afirma Nostra Santa Mare. Es un Reculliment y Retiro interior ques sent en l'anima; que apareix que ella te altres sentits, com açi los exteriors. De modo que allí, en si mateixa, apareix se ve apartar del bullici destos exteriors. Y aixi algunas vegades, se las na aporta tras sí. De modo que li dona gana de tancar los ulls y de no oir ni veurer ni entendre sino solament allo, en que l'anima, a les hores se ocupa que es tractar ab Deu a solas. Aquí nos pert ningún sentit ni Potencia que tot està enter. Pero están per a emplearse en Deu. Aço, a qui lo señor ho ha donat se será faci lo de entendrer y aquí nos No. A lo menos serán menester nostras paraulas y comparacions. Est es lo Reculliment Sobrenatural. Lo qual se diu tal: perque nos posseheix, ni alcança ab propia diligencia e industria de l'anima, com lo Primer. Sino per sola y pura Bondat y Misericordia Divina li es comunicat y infundit,, que per esta causa, se diu també infús (...).

Lo tercer grau de quietut, se explica per Nostra Sra Mare Teresa dient que dest Reculliment ço es del referit. Veu moltes vegades una quietut y pau interior que esta lanima; que no li apareix si falta cosa; que fins lo parlar la cança; dic a lo queço es lo rezar y meditar. No volria, sino amar $\mathrm{Y}$ aixi dura rato y encara ratos.

Lo quart grau de unió se explica per N. Sra M. Teresa. Alguna vegada y moltes vegades enten lanima que està unida sola la voluntat y se enten molt clar a lo que pareix. Dic clar, perque, com dic a està tota lo que pareix. Se enten que està tota empleada en Deu y que veu lanima la falta de poder estar ni obrar en altra cosa y las altres dos Potencias están libres per a negocis y obres del servei de Deu. En fi van iuntas Martha y Maria. Lo pregunti al pare Francisco. Si seria engany aço perque me portava abovada i em diguè que moltes vegades si succehia (...). Diu apres la santa quant la unio es de totas la potencias es molt diferent. Perque en ninguna cosa podan obrar. Perque lo Enteniment està coma espantat. La Voluntat ama mes que enten; però no entèn si ama, ni que fa. De manera que pugue dir la Memoria a mon parer, no hi ha ninguna; ni Pensament ni encara a les hores están los sentits desperts; sino com qui los perde. Per a emplear mes lanima en lo que goza, à mon parer. Perque aquell breu rato, se pert. Passa prest. En la riqueza que resta en lanima de Humiltat y altres Virtuts y desitgos; se enten lo gran Be que li vinguè de aquella Mercè. Pero nos pot dir lo que es. Perque, encara que lanima se done à entendrer; no sab com entendreho ni com dir-ho. A mon parer esta mercè, si es vertadera es la maior mercè; de las que Nostre Señor fa en est camí espiritual, à lo menos de las grans.» 15

Des del meu punt de vista, Antoni de Sant Maties dóna suport al «deixament», però amb matisos. No preconitza la interpretació lliure dels Evangelis, que havia caracteritzat els «deixats» de l' època d'Isabel de la Cruz. Nega la via sensitiva; no refusa la jerarquia eclesiàstica, ni les formes de pietat tradicionals. Són perceptibles les influències de San Juan de la Cruz o Francisco de Osuna, a la crítica als bullanguers

15 Ibidem, 481,482 i 483.

SCRIPTA, Revista internacional de literatura i cultura medieval i moderna, núm. 8 / desembre 2016 / pp. 287-300 ISSN: 2340-4841 · doi:10.7203/SCRIPTA.8.9300 
i dissoluts, en pretendre apaivagar l'enteniment de les visionàries. També té molt present al pare Tomás de Jesús i la recerca de la perfecció a partir de la mortificació dels sentits. Segueix Santa Teresa, però llegint-la en clau d'autocontrol emocional i de sentit de la seva pròpia excepcionalitat.

La virtut, per a ell, es podia aconseguir especialment amb la mortificació de la vista. Amb la mortificació i la negació pretenia combatre les acusacions formulades pels dominics De la Fuente i Orellana en relació a les visions i revelacions sorgides en el moment de la unió amb Déu defensat per la mare Teresa.

\section{Conclusions}

El recel cap a la religiositat femenina ja estava instal lat a l' època de Teresa, malgrat que ella representés la voluntat d'equilibri permanent entre la realitat i l'imaginari, entre el món contemplatiu i la vida activa, $\mathrm{i}$ intentés rebaixar la transcendència de les seves pròpies vivències. Teresa de Jesús marcaria, al llarg de la seva vida, la frontera de legitimitat de l'imaginari religiós femení. Es va quedar en el límit del que una dona podia fer i dir. La seva obra va suscitar prevencions, però acabà essent acceptada perquè va aconseguir unir, en tot moment, la religiositat institucional i el seu carisma personal.

Les generacions de religioses següents a Teresa varen viure de ple l'impacte de ls Contrareforma i el fracàs de les apostes per la tolerància ideològica. Els marcs històrics canviaren. El racionalisme preventiu sembla augmentar a l'àmbit eclesiàstic desde finals del segle XVI i culmina amb Gerónimo Planas, un dels tractadistes amb majors prevencions cap al món visionari femení.

Paral lelament, fra Antoni de Sant Maties Carbó no censurava pas les monges dels seus convents per llurs revelacions o visions ver la unió mística amb Déu, però la mortificació, que recomanava, pretenia buidar l'ànima de tot tipus d'afeccions. A l'obra de Sant Maties, en tot moment, hi rau una voluntat de ressaltar que la generositat divina està per sobre del carisma individual. Mentre a Santa Teresa, en el moment de la unió amb Déu, les criatures, d'alguna manera, segueixen estan presents, en Sant Maties han desaparegut i només es troben Déu i l'ànima.

El prevenció davant el món visionari femení va influïr a l'estancament de les beatificacions i canonitzacions de religioses, posteriors a Teresa de Jesús. Només algunes arribaren a la condició de Venerable i moltes d'elles foren estigmatitzades com a heterodoxes. 


\section{Bibliografia}

Alabrús, R. M. i García Cárcel. R. (2015) Teresa de Jesús. La construcción de la santidad femenina, Madrid, Cátedra.

Álvarez, T. (1965) Introducción a la edición facsímil de Camino de perfección, Ed. Facsímil, Roma, Políglota Vaticana.

Ángeles, J. de los (1595) Diálogos de la conquista del Reino de Dios, Palencia, Ed. Ángel González.

Callado, E. (2016) «Cuatro amigos. Teresa de Jesús, Francisco de Borja, Fray Luis Bertrán y Juan de Ribera» dins Emilio Callado (ed.), Viviendo sin vivir en mí. Estudios en torno a Teresa de Jesús en el $V^{o}$ Centenario de su Nacimiento, Madrid, Sílex.

Caro Baroja, J. (1978) Las formas complejas de la vida religiosa: religión, sociedad y carácter en la España de los siglos XVI y XVII, Madrid, Akal.

Comes, A. (1981) «Un escriptor místic català del segle XVIII: Fra Antoni de Sant Maties» dins A. Comes, Discurs de recepció en la Reial Acadèmia de Bones Lletres. Barcelona.

Daza, F. (1610) Historia, vida y milagros, éxtasis y revelaciones de la Bienaventurada Virgen Santa Juana de la Cruz, de la Tercera Orden de Nuestro Padre San Francisco, Madrid, Luis Sánchez.

Gras, M. (2013) Diccionari d'Autors i Obres de religiosos carmelites descalcos a la Província de Sant Josep de Catalunya $i$ terres de parla catalana (1586-1835).

García Cárcel, R. i Moreno, A. (2000) Inquisición. Historia crítica, Madrid, Temas de Hoy.

García Hernán, E. (2013) Ignacio de Loyola, Madrid, Taurus.

Horozco, J. (1588) Tratado de la verdadera y falsa profecía, Segovia, Juan de la Cuesta.

Huerga, A. (1978) Historia de los alumbrados. Los alumbrados de Extremadura (1570-1582), Madrid, Fundación Universitaria Española, I.

Imirizaldu, J. (1977) Monjas y beatas embaucadoras, Madrid, Ed. Nacional.

Jesús, T. De (2012) «Libro de la Vida», «Moradas del castillo interior» dins Obras completas, Madrid, $\mathrm{BAC}$

Kagan, R. (1992) Los sueños de Lucrecia. Política y profecía en la España del siglo XVI, Madrid, Nerea.

León, Fray L. (1992) La perfecta casada. Madrid: Espasa-Calpe.

Llamas Martínez, E. (OCD) (1972) Santa Teresa de Jesús y la Inquisición española, CSIC, Instituto «Francisco Suárez», Biblioteca Theologica Hispana, Serie 1a, Tomo 6.

Marcos, J. A. (2001) Mistica y subversiva: Teresa de Jesús (las estrategias retóricas del discurso místico), Madrid, Editorial de la Espiritualidad.

Martínez-Burgos García, P. (1997) «Los sueños de Eva: Visiones, éxtasis y raptos en la sensibilidad del Barroco», Valladolid, Publicaciones de la Universidad de Valladolid, BSAA, T. 63. 
Márquez, A. (1980) Los alumbrados. Orígenes y filosofía (1525-1559), Madrid, Taurus.

Morgado, A. (1999) Demonios, magos y brujas en la España Moderna, Cádiz, Servicio de Publicaciones de la Universidad de Cádiz.

Pascua, M. J. (2014) «El jo en l'escriptura religiosa femenina», Afers, 77.

Pérez, J. (2014) Cisneros, el cardenal de España, Madrid, Taurus.

Planas, G. (1634) Tratado del examen de las revelaciones verdaderas y falsas y de los raptos, Valencia, Viuda Juan Chrysostomo Garriz.

Poutrin, I. (1995) Le voile et la plume. Autobiographie et sainteté féminine dans l'Espagne moderne, Madrid, Casa de Velázquez

Ros, S. (1997) «Santa Teresa en su condición de mujer espiritual» en S. Ros (coord.). La recepción de los misticos: Teresa de Jesús y Juan de la Crur, Salamanca, Universidad Pontificia de Salamanca.

San José, M. de. (sense data o s/d) Papeles recogidos por Fray Lorenzo de la Madre de Dios, carmelita descalzo. Ms. 2176. Biblioteca Nacional de Madrid.

Sant Maties Carbó, A. de (1650) Cartes i epistolaris. Ms. 4164. Biblioteca de Catalunya; (s/d) Tractat de la perpetua mortificació exterior i interior. Ms 31. Biblioteca Universitaria de Barcelona

Tausiet, M. y Amelang, J. (2004) El diablo en la Edad Moderna, Madrid, Marcial Pons.

Vicens, G. Miscelánea político-eclesiástica, Ms. 1010, Biblioteca Universitaria de Barcelona.

Weber. A. (1996) Teresa de of Avila and the Rhetoric of Feminity, Princeton, Princeton University Press; (2003) «The Three Lives of the Vida: The Uses of Convent Autobiographia» dins M. Vicente (ed.). Women and texts and Autority in Early Modern Spain, Aldershot, Ashgate. 